\title{
A New Rig for Testing Textured Surfaces in Pure Sliding Conditions
}

\author{
Godi, Alessandro; Grønbæk, J.; Mohaghegh, Kamran; Klit, Peder; De Chiffre, Leonardo
}

Published in:

Tribology Letters

Link to article, DOI:

$10.1007 / \mathrm{s} 11249-013-0137-7$

Publication date:

2013

Link back to DTU Orbit

Citation (APA):

Godi, A., Grønbæk, J., Mohaghegh, K., Klit, P., \& De Chiffre, L. (2013). A New Rig for Testing Textured Surfaces in Pure Sliding Conditions. Tribology Letters, 50(3), 397-405. https://doi.org/10.1007/s11249-013-0137-7

\section{General rights}

Copyright and moral rights for the publications made accessible in the public portal are retained by the authors and/or other copyright owners and it is a condition of accessing publications that users recognise and abide by the legal requirements associated with these rights.

- Users may download and print one copy of any publication from the public portal for the purpose of private study or research.

- You may not further distribute the material or use it for any profit-making activity or commercial gain

- You may freely distribute the URL identifying the publication in the public portal

If you believe that this document breaches copyright please contact us providing details, and we will remove access to the work immediately and investigate your claim 


\title{
A new rig for testing textured surfaces in pure sliding conditions
}

\author{
A. Godi ${ }^{1}$, J. Grønbæk ${ }^{2}$, K. Mohaghegh ${ }^{1}$, P. Klit $^{1}$, L. De Chiffre ${ }^{1}$ \\ ${ }^{1}$ Department of Mechanical Engineering, Technical University of Denmark (DTU), \\ Produktionstorvet 425, 2800 Kgs. Lyngby, Denmark. \\ ${ }^{2}$ STRECON A/S, Stødagervej 5, 6400 Sønderborg, Denmark. \\ Corresponding author: Alessandro Godi (alego@mek.dtu.dk).
}

\begin{abstract}
Throughout the years, it has become more and more important to find new methods for reducing friction and wear occurrence in machine elements. A possible solution is found in texturing the surfaces under tribological contact, as demonstrated by the development and spread of plateau-honed surface for cylinder liners. To prove the efficacy of a particular textured surface, it is paramount to perform experimental tests under controlled laboratory conditions. In this paper a new test rig simulating pure sliding conditions is presented, dubbed Axial Sliding Test. It presents four major components: a rod, a sleeve, a housing and a stripwound container. The rod and the sleeve are the two surfaces in relative sliding motion; the stripwound container maintains a constant, but adjustable normal pressure and the housing serves as interface between the sleeve and the container. For carrying out the test, two machineries are necessary: a press to provide the normal pressure and a tensile machine to perform the axial movements. The test is calibrated so that the correspondence between the normal pressure and the container advancement is found. Preliminary tests are carried out involving a multifunctional and a fine turned rod against a mirror-polished sleeve. Qualitatively the multifunctional surfaces improve the friction conditions, but a more structured test campaign is required. It is furthermore assessed the repeatability of the test device, in order to rely on the results obtained. Ten repetitions made at the same pressure using the fine turned rod displayed good repeatability of the force results both in terms of average values and trends.
\end{abstract}

Keywords: machine elements; textured surfaces; axial sliding; test rig; friction. 


\section{Introduction}

The reduction of friction losses and wear occurrence in machine elements, together with the striving for reducing energy and fuel consumption in the transportation industry are issues whose importance has been growing over the years [1,2]. The world energy consumed to overcome friction lies around $30 \%$, while the economic costs associated with wear is higher than the $5 \%$ of the GDP of developed countries [3-6]. A possible solution has been deemed being surface texturing. Generally, "textured” or “engineered” surfaces are those which have been produced in a specific way in order to give one or more specific functions [7]. In this case the functions provided are lubrication capability (by means of lubricant reservoirs) accompanied by load bearing capacity of the surface. A typical instance is represented by plateau-honed surfaces for cylinder liners which have been widely used in the automotive industry in the last three decades. In these surfaces the finishing process removes the peaks which would be worn out during the run-in period but keeps part of the coarser texture from the pre-machining operation [8,9]. The resulting surface has a plateau area capable of bearing loads and deeper valleys able to retain lubricant (Fig. 1) [10].

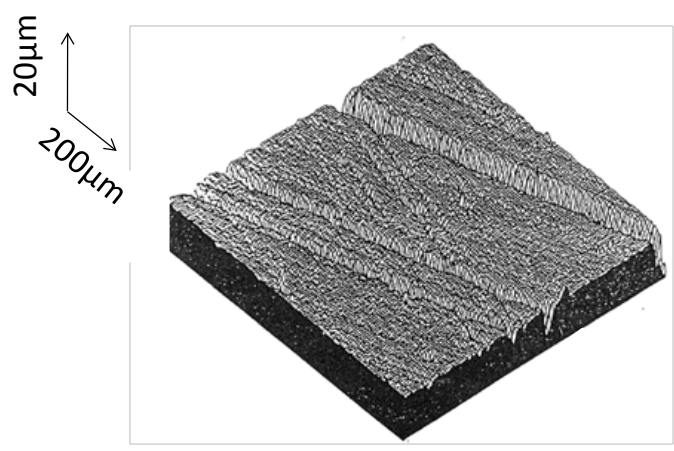

Fig.1. Isometric plot of a plateau-honed surface, adapted from [10].

There are several other ways to produce textured surfaces, encompassing adding, removing and moving material techniques [3]. In order to assess the efficiency of textured surfaces, experimental tests simulating real working conditions have to be performed. In literature, a high variety of studies can be found examining different tribological situations. Pettersson and Jacobson in [11], for example, used real hydraulic motor components when testing the efficacy of textured surfaces in reciprocating sliding conditions between a piston and a roller. Vrbka et al. [12] used instead an experimental apparatus consisting of two discs loaded against a roller in order to study the effect of surface texturing on rolling contact fatigue in mixed lubricated conditions. Recently, Ramesh et al. [13] have utilized standard pin-on-disk equipment to assess the friction reduction achievable by a dimpled surface when the texture is applied to the pin. In this paper a new experimental test apparatus for machine elements, designed and developed by the authors is presented. It is called Axial Sliding Test (AST). The AST can simulate any machine element presenting an axial movement between two counterparts under pure sliding conditions, such as a piston ring sliding in a cylinder liner. The test is a general one: it has been conceived to evaluate the effectiveness of textured surfaces, but it can be actually used for other purposes as for instance lubricants testing. The selection and pairing of materials, hardness, surface topography, surface coating and lubrication are in fact fully free. This test is an alternative to well-established test rigs examining sliding contacts, such as the Cameron-Plint tester [14,15], the pin-on-disk apparatus [16] or others. Compared to them, the AST offers the possibility of achieving high areas of contact and, most importantly, the specimens therein employed are specifically designed for permitting an easier realization of "multifunctional" textures, described in [17-19]. Some preliminary tests were in fact carried out in order to make an initial comparison between the performances of these surfaces and of regularly machined ones. Moreover, repeatability tests were also performed in order to determine the reliability of the results obtained with this new test rig.

\section{Axial Sliding Test apparatus description}

The test rig consists of four major components: a stripwound Strecon ${ }^{\circledR}$ container, a conical housing, a rod and a sleeve (Fig. 2). 


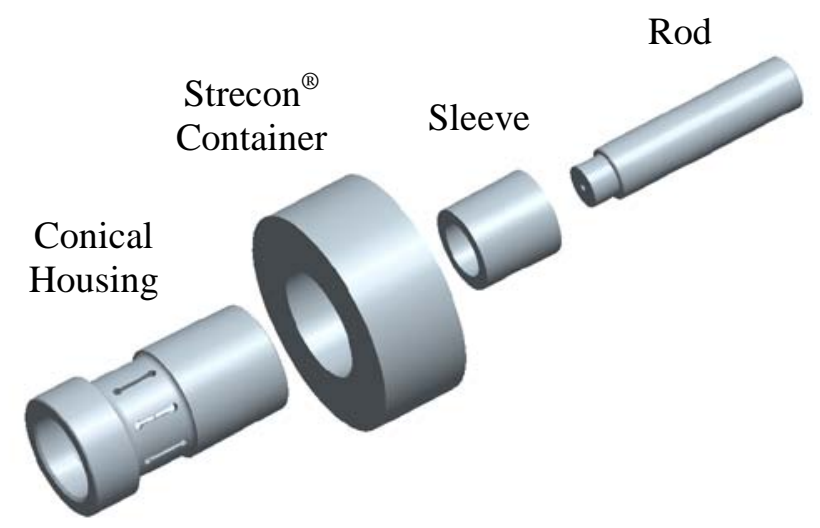

Fig.2. Axial sliding test major components.

During the experiments the only parts in relative motion with respect to each other are the rod and the sleeve, to which the tested surfaces are applied. The rod is in the present case a cylinder made of chromium-molybdenum-vanadium alloyed steel (Vanadis 6) with a hardness of 62HRC, diameter $\varnothing 38 \mathrm{~mm}$ and length equal to $135 \mathrm{~mm}$. The sleeve is a $60 \mathrm{~mm}$ long hollow cylinder made of the same material, but slightly harder (64HRC). Its inner diameter is nominally $50 \mu \mathrm{m}$ larger than the rod outer diameter, while the sleeve outer diameter is $\varnothing 58 \mathrm{~mm}$. The sleeve is placed inside the housing (Fig. 3, left), which is cylindrical on the inside and slightly conical $\left(1^{\circ}\right)$ on the outside. The fourth major component, the Strecon ${ }^{\circledR}$ container, envelops the conical housing and has the crucial function of keeping the normal pressure on the housing-sleeve system uniform.

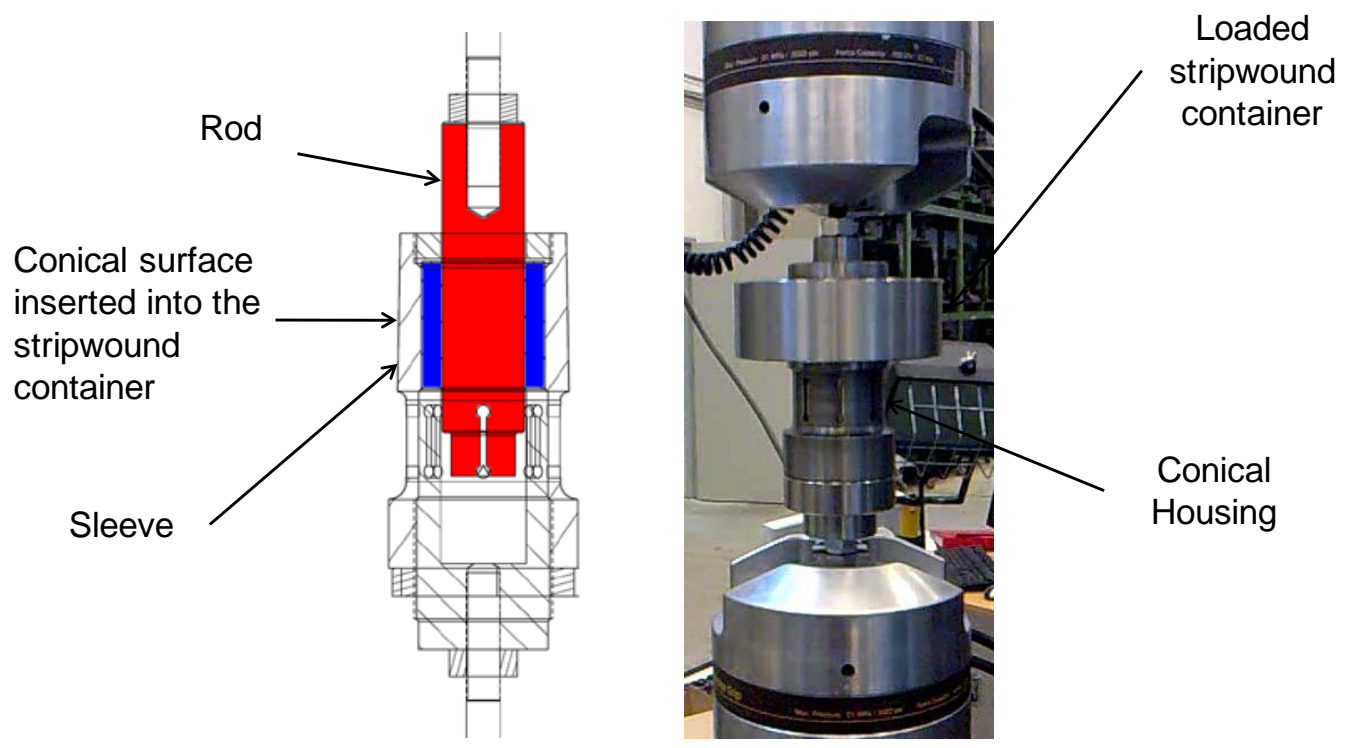

Fig.3. Axial section of the assembled AST rig without stripwound container (left); the apparatus mounted in a tensile machine (right).

\subsection{Stripwound container}

In order to guarantee the keeping of a constant pressure, a special production process has been used to realize the Strecon ${ }^{\circledR}$ container: the stripwinding technique. Developed over the last thirty years $[20,21]$, the stripwinding process consists in a $0.1 \mathrm{~mm}$ thick high-strength strip wound around a hardened core of high-alloyed tool steel (Fig. 4) [22,23]. 
Tribol Lett (2013) 50:397-405

DOI 10.1007/s11249-013-0137-7

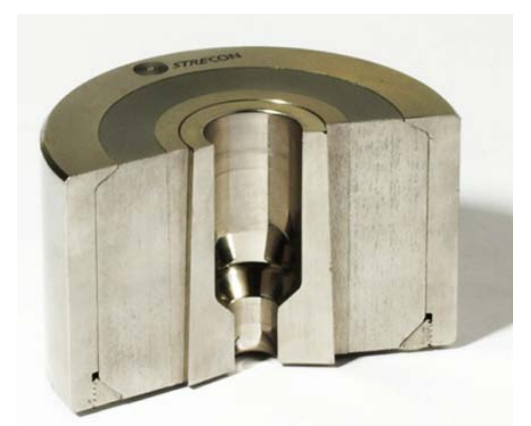

Fig.4. Stripwound Strecon ${ }^{\circledR}$ container section [20]. The AST container presents the inner surface with the same degree of conicity as the housing.

During the winding process the strip material is loaded with a controlled back tension: varying it from layer to layer provides an optimal stress distribution (Fig. 5) [22,23]. The equivalent stress is distributed over hundreds of layers, thus avoiding stress concentrations [23]. As a result, the peak stresses in the stripwound containers lie within the elastic limits: no plastic deformation and pressure losses are observed [22,23]. The inner surface of the container used for the Axial Sliding Test has been ground to the same angle $\left(1^{\circ}\right)$ as the housing. The low cone angle keeps the container self-locking on the housing and thus the maintaining of a constant pressure is achieved.

\section{Conventional stress ring}

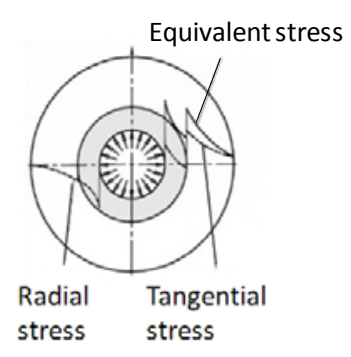

STRECON ${ }^{\circledR}$ prestressed container

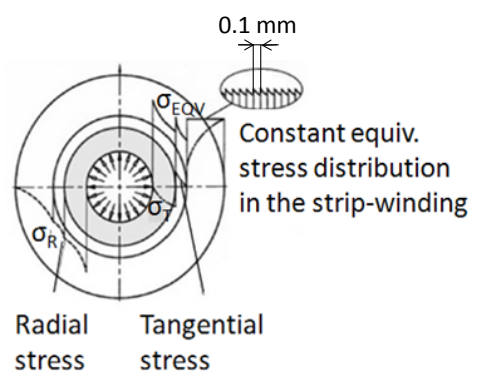

Fig.5. Stress distribution in a conventional stress ring (left) and in a stripwound Strecon ${ }^{\circledR}$ container (right) [20].

\section{AST set up}

In order to be performed, the axial sliding test needs two machines: a hydraulic press and a tensile test machine.

\subsection{Pressing operation}

The first operation to be performed is to load the AST apparatus. The assembled test rig is placed in the hydraulic press and the container is pressed down the housing increasing the normal pressure at a constant rate with its advance. The incremental advance of the container at every press stroke is known thanks to a series of pressure rings with calibrated heights beforehand arrayed around the housing. A mathematical model based on the theory of multiple shrink fitted rings [24] has been used in order to correlate the advance, the sleeve inner diameter shrinkage and the normal pressure. In order to verify and calibrate the model, the sleeve shrinkage as a function of the container progress is experimentally determined (Fig. 6). In the first experiment the rod is not assembled in the test rig. The loading operation is repeated several times and before each stroke the sleeve inner diameter was measured with a three-point internal micrometer at different axial positions. When the sleeve and the housing come to full contact, the sleeve diameter reduces proportionally with the container advancement (Fig. 6). The reduction is estimated being $13 \mu \mathrm{m}$ every $\mathrm{mm}$ of progress of the Strecon ${ }^{\circledR}$ container. The experiment is then repeated with a hollow rod (Ø26 mm inner diameter) assembled with the sleeve. The reduction is now estimated being $9 \mu \mathrm{m}$ every mm of progress of the container. The model has thus been calibrated and the normal 
Tribol Lett (2013) 50:397-405

DOI 10.1007/s11249-013-0137-7

pressure increase is deemed being $34 \mathrm{MPa}$ every mm the stripwound container slides down the housing. This is based on the interference generated between the sleeve and the rod, like in shrinkfitting operations [24].

Once the pressing operation is completed, the whole apparatus is transferred to the second station, the tensile test machine.

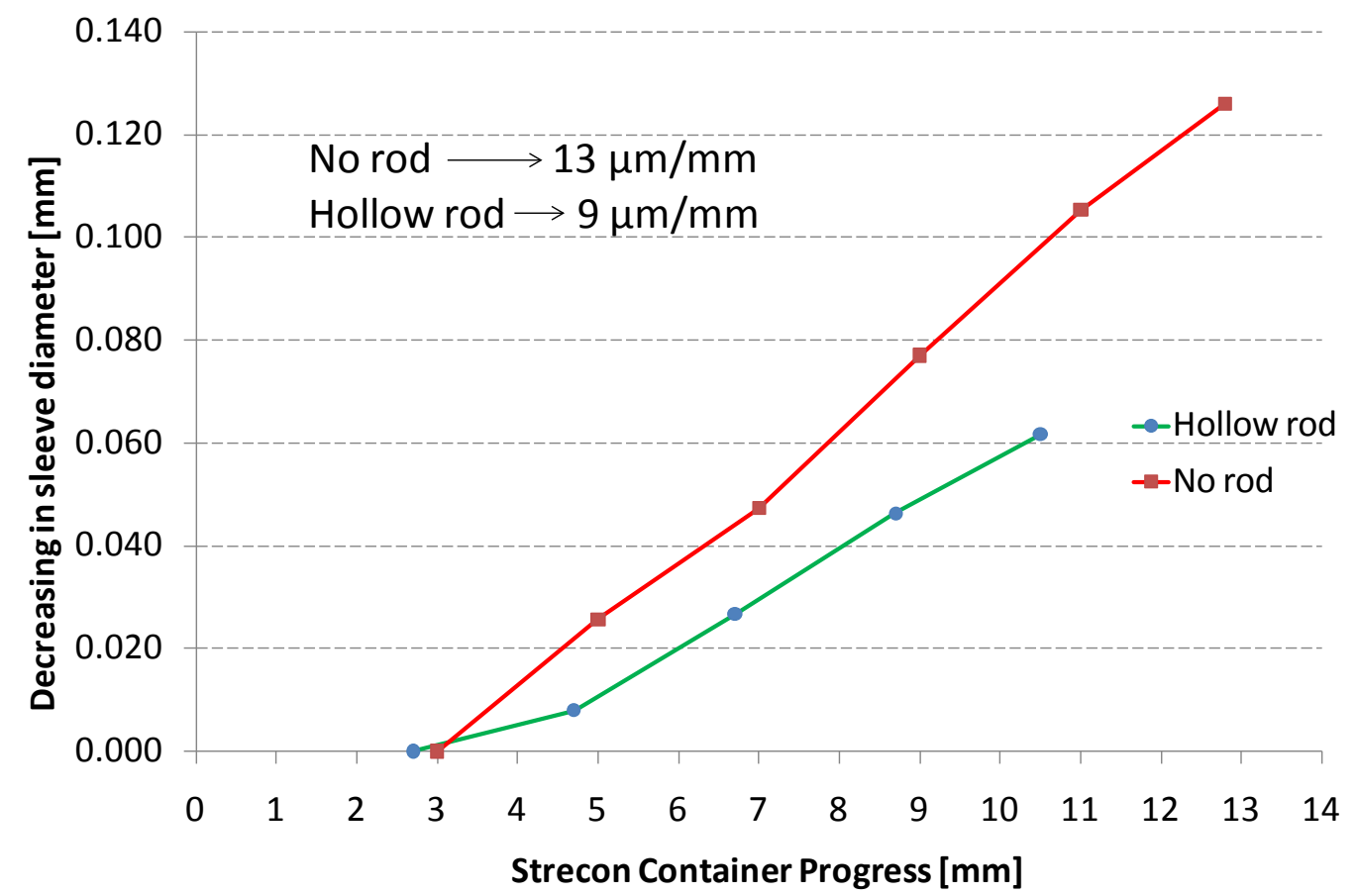

Fig.6. Sleeve inner diameter reduction as a function of the container progress: the "no rod" and "hollow rod" configurations.

\subsection{Tensile machine}

The loaded apparatus is mounted in a tensile test machine with a load capability of $100 \mathrm{kN}$ both in tension and in compression (Fig. 3, right). The test is at last carried out making the rod sliding back and forth inside the sleeve according to a predefined program. Throughout the test, the force necessary to keep the set frequency (or speed) constant is measured by a calibrated load cell. In Fig. 7 are shown load and position results of an Axial Sliding Test performed following a sinusoidal movement: 10 cycles with a frequency of $0.2 \mathrm{~Hz}$ and a sampling frequency of 10 points/s. The rod is slid $15 \mathrm{~mm}$ back and forth, meaning that the sliding speed varies between $0 \mathrm{~mm} / \mathrm{s}$ (dead centers) and approximately $19 \mathrm{~mm} / \mathrm{s}$ at the center of the stroke. In the presented example, the load is comprised between 1.5 and $-1.5 \mathrm{kN}$. 
Tribol Lett (2013) 50:397-405

DOI 10.1007/s11249-013-0137-7

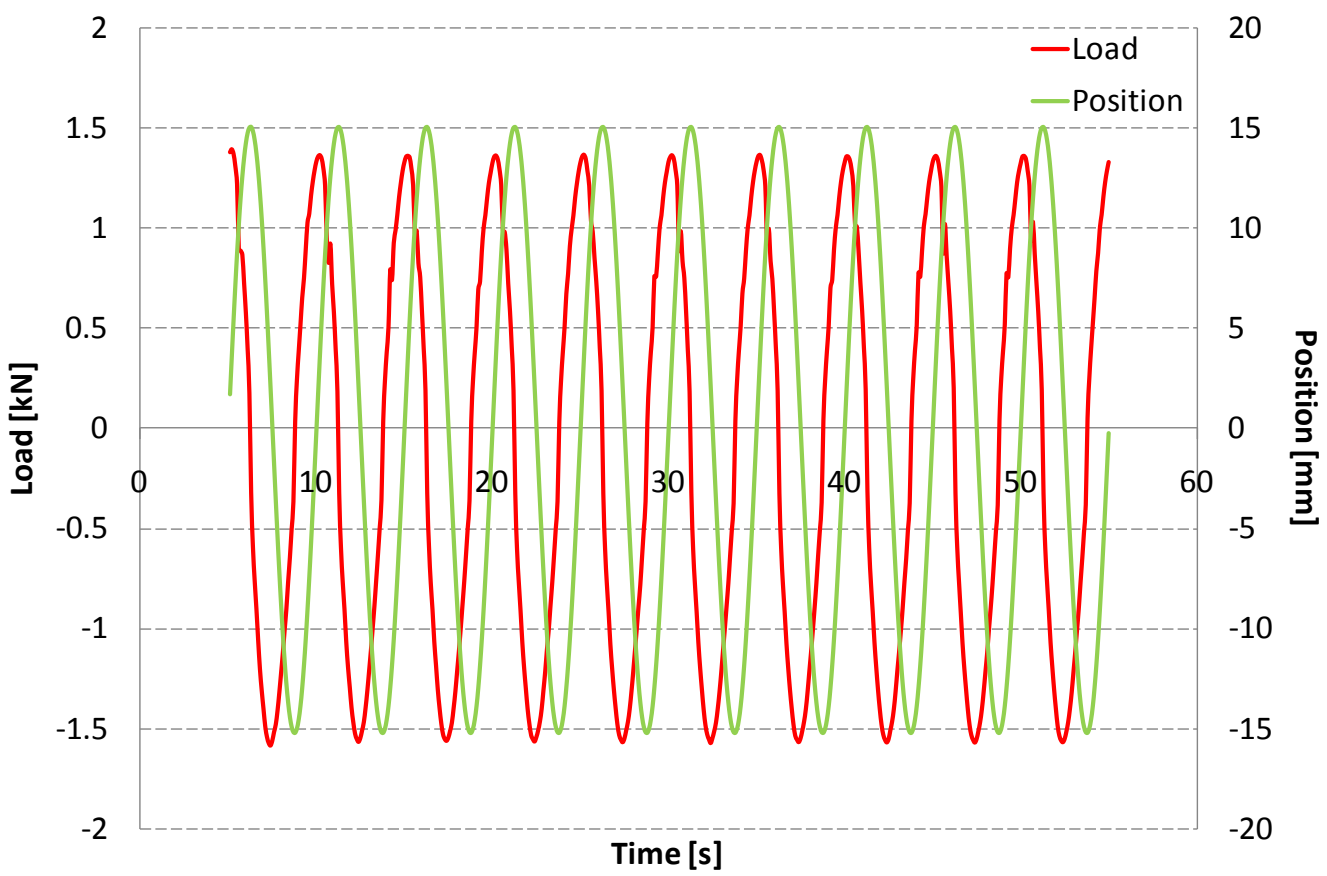

Fig.7. Load and position results of an Axial Sliding Test following a sinusoidal movement.

\section{Preliminary tests}

As stated above, despite it offers numerous testing possibilities, the Axial Sliding Test has been conceived for assessing the efficacy of engineered surfaces. Of a particular interest is the testing of a new typology of textured surfaces, the so-called multifunctional (MUFU) surfaces [17-19]. They are produced through a two-step manufacturing process, namely a primary hard-turning operation which provides a periodic texture pattern, followed by a robot assisted polishing (RAP) operation to create the plateau regions able to bear loads [17-19]. An example of multifunctional surface applied to an AST rod is shown in Fig. 8, bottom profile. Thanks to the high control of the RAP process, it is theoretically possible for the plateau bearing area to assume any value between $0 \%$ and $100 \%$ [17-19].

The major purpose of the Axial Sliding Test is therefore to prove the effectiveness of such surfaces compared to others produced through conventional manufacturing processes (turning, grinding, etc.). For the preliminary tests three specimens have been realized, whose roughnesses were measured before and after testing with a calibrated independent datum inductive profilometer (Form Talysurf with 50mm maximum traversing length). They are namely a mirror-polished sleeve with extremely low roughness $(\mathrm{Ra}<0.02 \mu \mathrm{m})$, a rod turned with a feed rate of $0.1 \mathrm{~mm}$ (finely turned) and a multifunctional rod with a bearing area of the plateaus equal to $40 \%$ (Fig. 8). The specimens were then lubricated with high-viscosity synthetic grease based on perfluorinated polyether oil (BARRIERTA ${ }^{\circledR}$ L55/3) [25].

The tests were carried out as previously described, since Fig. 7 is taken from a test performed with the multifunctional rod. 30mm constant-speed ramps (not shown in the figure) preceded and followed the sinusoidal movement in order to utilize the central zone of the rod. A number of tests were performed at different normal pressures, i.e. at different advances of the stripwound container. Precisely, the friction forces were recorded each $0.2 \mathrm{~mm}$ advance of the container. In order to start the experiments, a reference point (a reference pressure ring combination) is needed. Initially, the ring combination which would not allow a manual movement of the rod after the pressing operation was chosen as reference point. It is a subjective method and therefore not an ideal one, but it allows the screening out of loose combinations. For each test the positive friction forces when the rod is at its maximum speed (rod position equal to 0 according to Fig. 7) were taken and averaged. The test results are plotted in Fig. 9. The ordinate axis displays the friction stresses obtained dividing the measured forces by the nominal area of contact. The abscissas, instead, represent the normal pressure increase relatively to a zero point. This zero point is not the manually determined reference; rather it is the first combination which requires loads higher than $0.5 \mathrm{kN}$. This artificial reference, which corresponds to still low friction stresses, has the advantage 
Tribol Lett (2013) 50:397-405

DOI 10.1007/s11249-013-0137-7

of being based on a specific number rather than a subjective feeling. Moreover, by discarding the results at extremely low loads, it helps to pair otherwise offset curves. The error bars shown in Fig. 9 represent the standard deviation calculated from the 10 results each test provides.
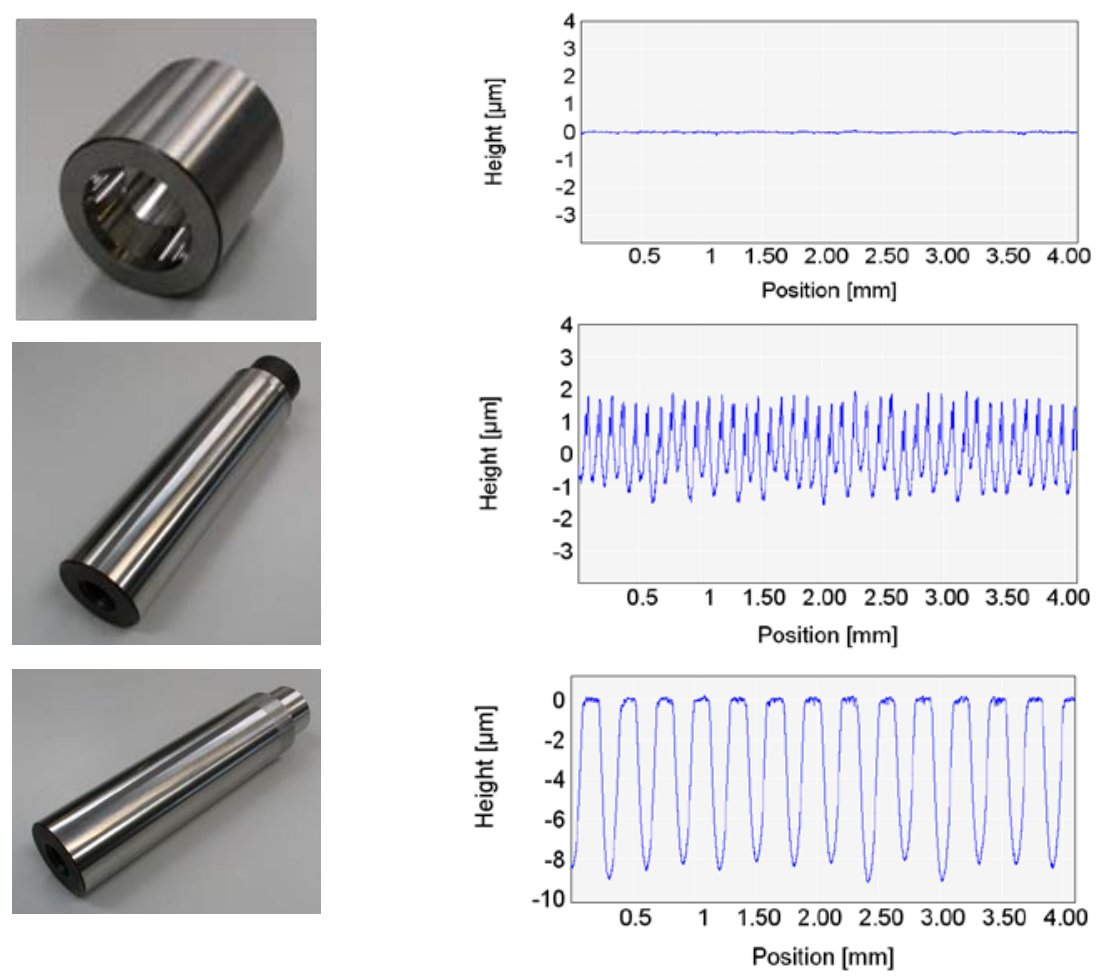

Fig.8. Specimens used for the preliminary tests and their roughness profiles: a mirror polished sleeve (top), a fine turned rod (center) and a rod with a multifunctional surface (bottom). The profiles were taken along the axial direction.

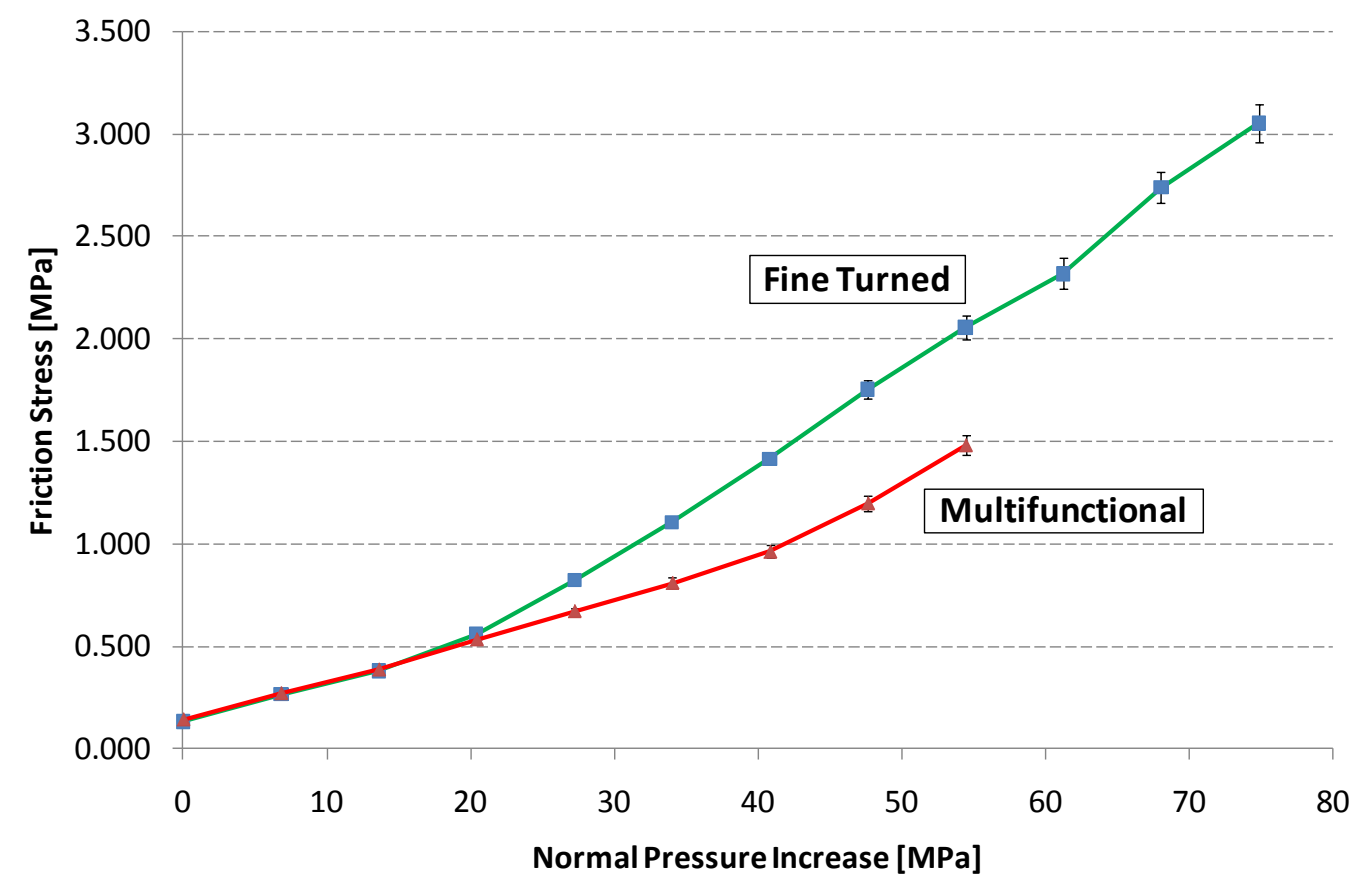

Fig.9. Friction stresses comparison between a fine turned and a multifunctional rod loaded with a polished sleeve. 
Tribol Lett (2013) 50:397-405

DOI 10.1007/s11249-013-0137-7

\section{Discussion}

With reference to Fig. 9, the artificial reference couples very well the two curves, being the friction stress 0.142 and $0.133 \mathrm{MPa}$ for the multifunctional and the fine turned rod respectively. The two curves show to increase coherently for the first $15 \mathrm{MPa}$ of normal pressure increase from the zero point, to eventually diverge after that limit. Due to the high lubricant viscosity it is possible that a thin film separating the two surfaces is still maintained until the pressure is $15 \mathrm{MPa}$, hence the similar behavior. After the limit, asperity contact begins to occur and the system enters in a mixed lubrication regime [26]. The friction force appears to increase more rapidly for the combination fine turned rod - polished sleeve than the multifunctional rod - polished sleeve one. By fitting a line through the observed data, the friction coefficient can be estimated. For the combination involving the fine turned rod $\mu=0.046$, while for the one involving the multifunctional $\operatorname{rod} \mu=0.027$. The multifunctional surface seems to assure a better friction reduction than the fine turned one.

Nevertheless, it must be remarked that the results obtained are just the outcomes of preliminary tests, performed mainly with the purpose of improving the understanding of the AST apparatus and the machineries involved. The high viscosity lubricant, for example, was chosen to protect the surfaces for future usage (no wear marks were indeed detected in the post-test examination). The results, though, could have been partly biased by the high lubricant performances. Only a qualitative assessment of the multifunctional surfaces effectiveness can be provided after these tests, but not a definitive answer.

\section{Repeatability tests}

When a new test rig is introduced, it is important to assess the reliability of the results achieved. That can be done by testing whether or not the device provides the same results if repeatedly tested under the same conditions. For this purpose the fine turned rod was tested again. A less effective lubricant Texaco Multifak ${ }^{\circledR}$ EP2 with a viscosity of $173 \mathrm{cSt}$ at $40^{\circ} \mathrm{C}$ [27] was used, which is more suitable for experimental purposes. The reciprocating program was also changed from a sinusoidal wave to square wave ensuring a constant speed throughout the stroke. The speed was set to $1 \mathrm{~mm} / \mathrm{s}$ along a $30 \mathrm{~mm}$ stroke. At the end of the stroke, a waiting time was observed, initially set to $10 \mathrm{~s}$, later reduced to $2 \mathrm{~s}$ to shorten the test duration. The test was performed in two different days. The first day, 10 cycles at a $27 \mathrm{MPa}$ were performed (Fig. 10) and afterwards, the rig was disassembled. The obtained $17 \mathrm{kN}$ of friction force (average of the five last positive periods) lead to $3 \mathrm{MPa}$ of friction stresses, more than three times higher than the ones obtained with the previous lubricant. The second day, the 10 cycles at $27 \mathrm{MPa}$ were repeated 10 times consecutively without disassembling the rig between each test (Figs. 11, 12). Looking at Fig. 11, both the shape and the values of the friction forces are in agreement to what measured on the first day. The repeatability of the results is confirmed by the temporal alignment of the measured friction forces of Fig. 12. In Fig. 13 the average friction forces, calculated on the last five periods of each repetition are plotted. The red column represents the test on the first day, the others the 10 repetitions of the second day. The error bars represent the average range between the max and min forces measured during the stroke. The range was chosen due to the systematic nature of the force trends. The test showed a slightly increasing trend in the first 5 repetitions and then stabilizing afterwards. The increment can be explained by a redistribution of the grease on the surface of the rod. This hypothesis is supported by a reduction in the force ranges and by force values similar to the ones measured the first day. In the first day, in fact, some tests were carried out to find a new reference point, which distributed the lubricant more uniformly. Generally speaking the test showed an extremely satisfactory repeatability, both in terms of force trends, all descending, and values, all comprised between $16 \mathrm{kN}$ and $17 \mathrm{kN}$ and all well within the error bars. 
Tribol Lett (2013) 50:397-405

DOI 10.1007/s11249-013-0137-7

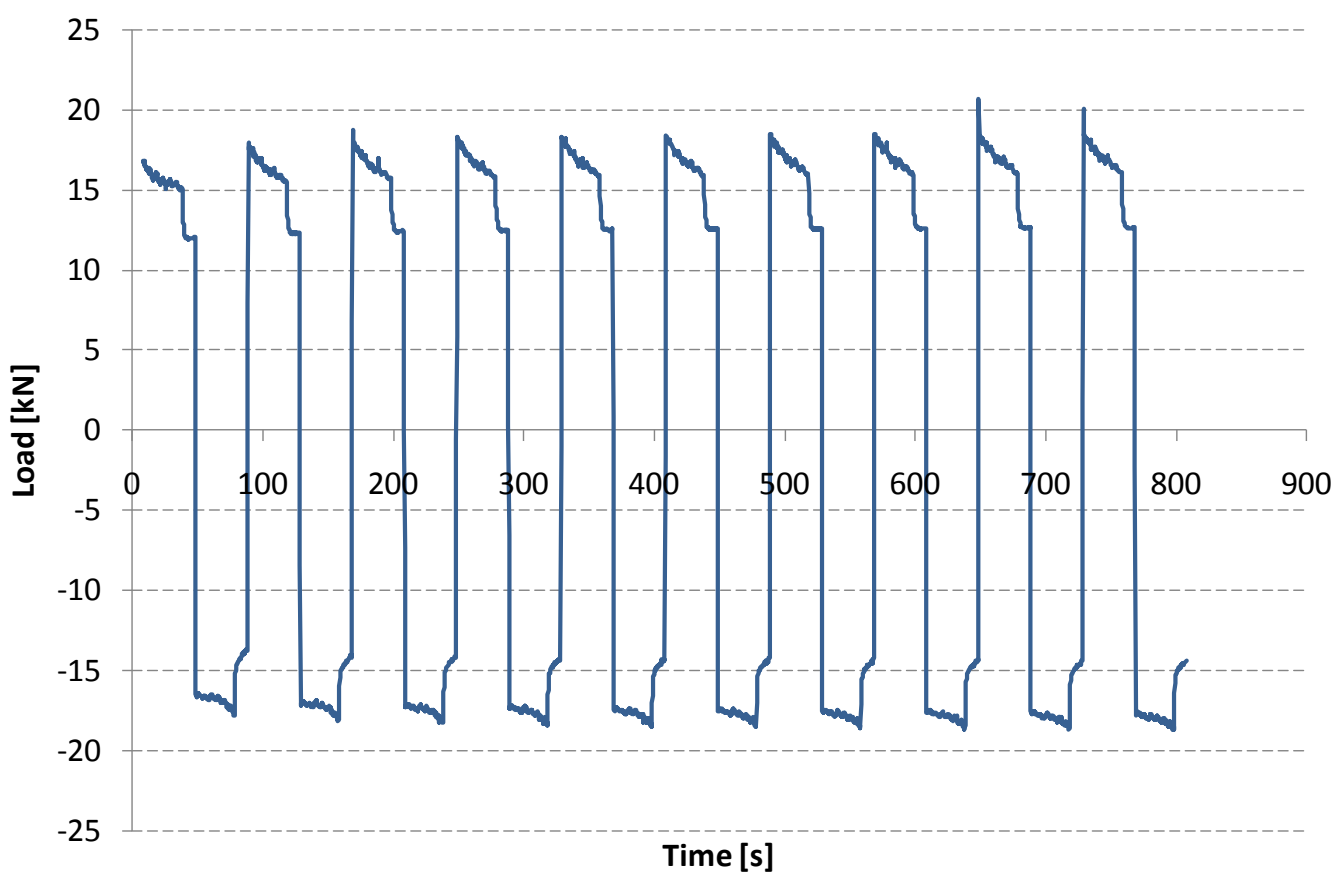

Fig.10. Fine-turned rod tested at $27 \mathrm{MPa}$ on the first day.

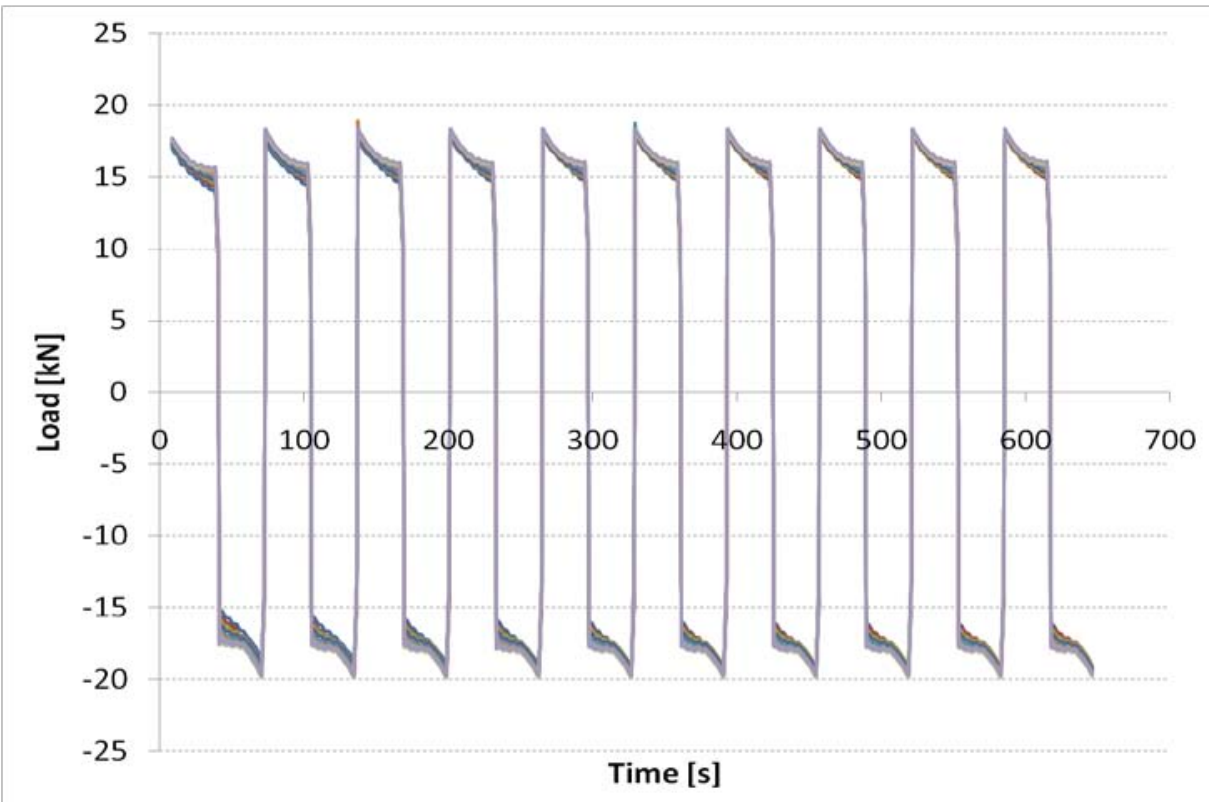

Fig.11. Superimposition of the 10 repetitions at $27 \mathrm{MPa}$ performed with a fine-turned rod. 
Tribol Lett (2013) 50:397-405

DOI 10.1007/s11249-013-0137-7

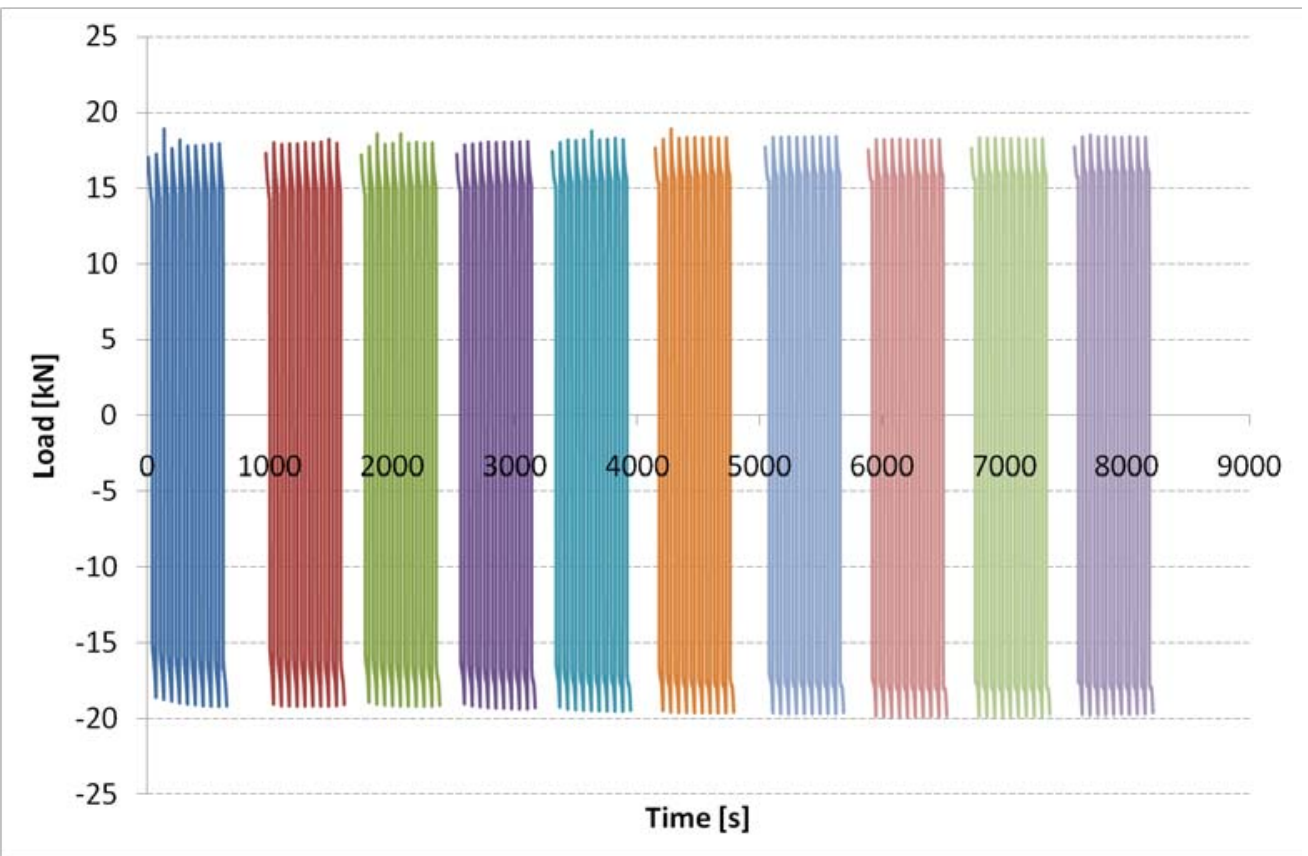

Fig.12. Alignment of the 10 repetitions at $27 \mathrm{MPa}$ performed with a fine-turned rod.

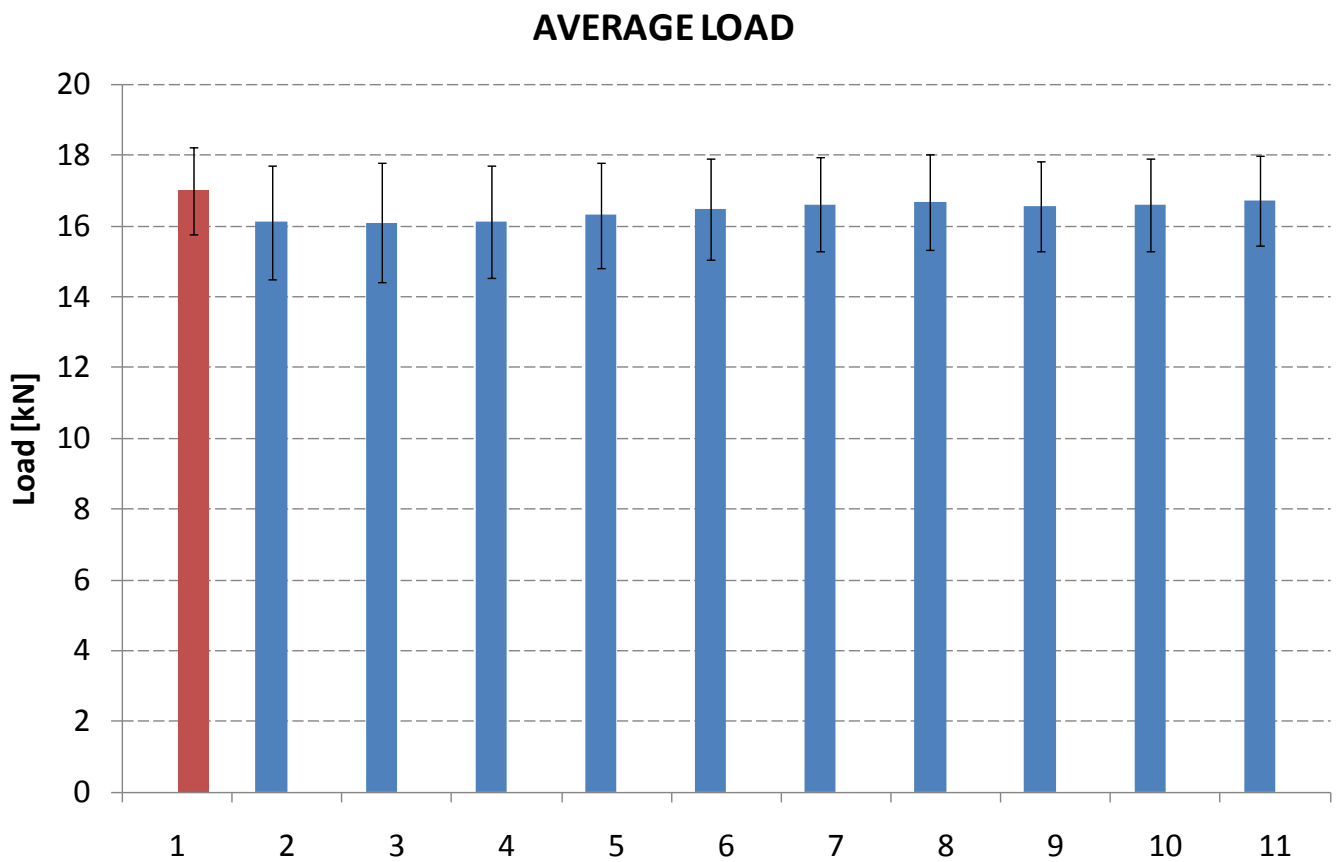

Fig.13. Average friction forces during the repeatability tests.

\section{Conclusions}

In this paper a newly developed test rig simulating pure sliding conditions between two machine elements is presented. Named AST, it has been designed for testing textured surfaces, in particular multifunctional surfaces, although the range of applications could be quite broad. The test apparatus consists of four main components, of which two perform the relative sliding: the rod and the sleeve. The Strecon ${ }^{\circledR}$ container manufactured using the stripwinding technique allows the keeping of a constant normal pressure throughout the whole experiment. Two machines are needed for performing the test: a press to load the system and a tensile test machine for ensuring the rodsleeve relative movement. The test is calibrated so that the normal pressure increase for every mm 
Tribol Lett (2013) 50:397-405

DOI 10.1007/s11249-013-0137-7

of advance of the stripwound container is known. Preliminary tests are carried out comparing the friction forces associated to a multifunctional and a fine turned rod when they both are loaded by a mirror-polished sleeve. These initial tests prove qualitatively that a multifunctional surface can be a valid candidate for reducing friction forces in machine elements subjected to pure sliding, but a more structured test campaign is needed. Repeatability tests were also carried out using again the fine-turned rod displaying an extremely satisfactory repeatability both in terms of average force values and curve shape.

\section{REFERENCES}

[1] Erdemir, A.: Review of engineered tribological interfaces for improved boundary lubrication. Trib. Int. 38 (2005), 249-256.

[2] Stachowiak, G., Podsialdo, P.: 3-D Characterization, Optimization and Classification of Textured Surfaces. Tribol. Lett. 32, 13-21 (2008).

[3] Bruzzone, A.A.G., Costa, H.L., Lonardo, P.M., Lucca, D.A.: Advances in engineered surfaces for functional performance. CIRP Ann. Manuf. Technol. 57, 750-769 (2008).

[4] Williams, J.A.: Engineering Tribology. Oxford University Press, Oxford, UK, p.1 (1994).

[5] Jost, H.P.: Lubrication (Tribology) - A Report on the Present Position and Industry's Needs. Her Majesty’s Stationery Office, London, UK, 1-79 (1966).

[6] Jost, H.P.: Tribology - Origin and Future. Wear 136 (1), 1-17 (1990).

[7] Evans, C.J., Bryan, J.B.: “Structured”, “Textured” or “Engineered” Surfaces. CIRP Ann. Manuf. Technol. 48(2), 541-556 (1999).

[8] Stout, K.J., Spedding, T.A.: The characterization of internal combustion engine bores. Wear 83, 311-326 (1982).

[9] Whitehouse, D.J.: Some theoretical aspects of a practical measurement problem in plateau honing. Int. J. Prod. Res. 21(2), 215-221 (1983).

[10] Stout, K.J., Sullivan, P.J., Dong, W.P., Mainsah, E., Luo, N., Mathia, T., Zahouani, H.: The development of methods for the characterization of roughness in three dimensions. Commission of the European Communities, UK (1993).

[11] Pettersson, U., Jacobson, S.: Textured surfaces for improved lubrication at high pressure and low sliding speed of roller/piston in hydraulic motors. Tribol. Int. 40, 355-359 (2007).

[12] Vrbka, M., Šamánek, O., Šperka, P., Návrat, T., Křupka, I., Hartl, M.: Effect of surface texturing on rolling contact fatigue within mixed lubricated non-conformal rolling/sliding contacts. Tribol. Int. 43, 1457-1465 (2010).

[13] Ramesh, A., Akram, W., Mishra, P.S., Cannon, A.H., Polycarpou, A.A., King, W.P.: Friction characteristics of microtextured surfaces under mixed and hydrodynamic lubrication. Tribol. Int. 57, 170-176 (2013).

[14] Phoenix Tribology Ltd: Plint Tribology Products. www.phoenix-tribology.com. Accessed $10^{\text {th }}$ February 2013.

[15] Plint, A.G., Plint, M.A.: Test procedure for rapid assessment of frictional properties of engine oils at elevated temperatures. Tribol. Int. 17(4), 209-213 (1984).

[16] Standard ASTM G99-04a: Standard Test Method for Wear Testing with a Pin-on-Disk Apparatus (2004). http://enterprise2.astm.org/DOWNLOAD/G99-04A.1375232-1.pdf. Accessed

$10^{\text {th }}$ February 2013. 
Tribol Lett (2013) 50:397-405

DOI 10.1007/s11249-013-0137-7

[17] Friis, K.S., Godi, A., De Chiffre, L.: Characterization and robust filtering of multifunctional surfaces using ISO standards. Meas. Sci. Technol. 22 (2011), art.125101.

[18] Grønbæk, J.: Generation of multifunctional surfaces by hard-machining followed by Robot Assisted Polishing. Proceedings of the "Functional Surfaces in Mechanical Systems" Conference, DTU, Denmark, (2011).

[19] Godi, A., Friis, K.S., De Chiffre, L.: Characterization of multifunctional surfaces during fabrication. Proceedings of the $11^{\text {th }}$ euspen International Conference, Como, Italy, 92-95 (2011).

[20] Grønbæk, J.: Stripwinding of tool for bulk metal forming. Ph.D. Thesis, Technical University of Denmark (1981). (In Danish).

[21] Grønbæk, J.: Application of stripwinding tool to large reduction cold forging processes. Proceedings of the North American Manufacturing Research Conference (NAMRC-X), Hamilton, Canada, 225-232 (1982).

[22] Grønbæk, J.: Stripwound cold-forging tools - A technical and economical alternative. J. Mater. Process. Techn. 35, 483-493 (1992).

[23] Strecon A/S: The stripwinding principle. www.strecon.com. Accessed 30 ${ }^{\text {th }}$ November 2012.

[24] Sidenius, I.: Aksler. Kiler, fedre og splines. Krympning og roterende skiver. Kompendium til maskinelementer KP4, Polyteknisk Forlag, Denmark (1971). (In Danish).

[25] Klüber Lubrication: BARRIERTA ${ }^{\circledR}$ L55 series.

http://www.klubersolutions.com/pdfs/Barrierta\%20L\%2055.pdf. Accessed 30 ${ }^{\text {th }}$ November 2012.

[26] Schey, J.A.: Tribology in Metalworking - Friction, Lubrication and Wear, American Society for Metals, Metals Park, Ohio, $72-77$ (1984).

[27] Texaco Multifak ${ }^{\circledR}$ EP 0,1,2. http://www.rolandjrobertdistributor.com/files/Multifak_ep.pdf. Accessed 29 ${ }^{\text {th }}$ November 2012. 